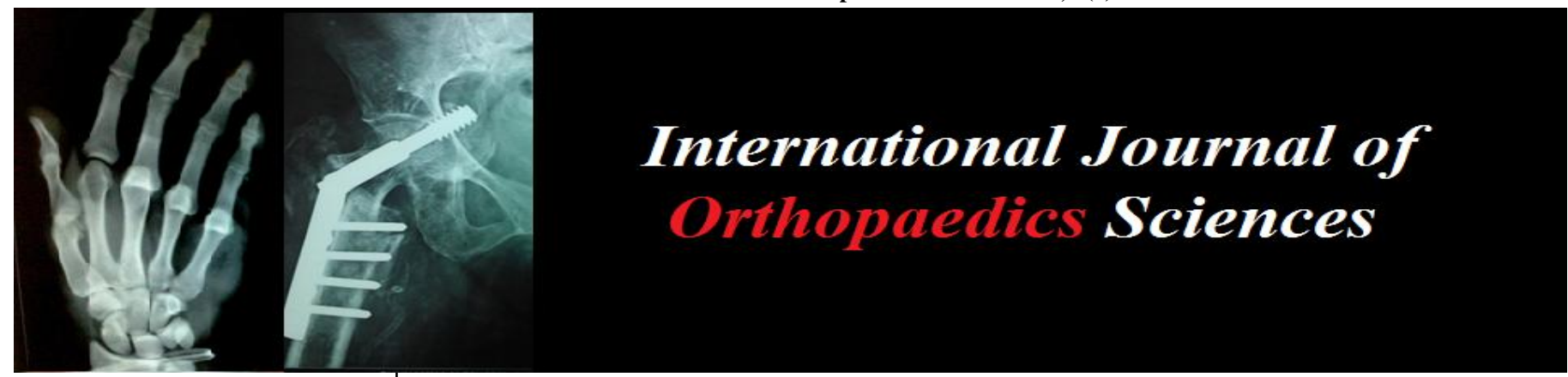

ISSN: $2395-1958$

IJOS 2018; 4(1): 864-866

(C) 2018 IJOS

www.orthopaper.com

Received: 14-11-2017

Accepted: 15-12-2017

Shah Waliullah

Asst Prof, Dept. of Orthopaedic Surgery, King George Medical

University, Lucknow,

Uttar Pradesh, India

\section{Vineet Sharma}

Professor, Dept. of Orthopaedic Surgery, King George Medical

University, Lucknow,

Uttar Pradesh, India

\section{RN Srivastava}

Professor, Dept. of Orthopaedic Surgery, King George Medical

University, Lucknow,

Uttar Pradesh, India

Yashodhara Pradeep

Professor, Dept. of Obstretics

and Gynaecology, King George

Medical University, Lucknow,

Uttar Pradesh, India

\section{AA Mahdi}

Professor \& Head, Dept. of Biochemistry, King George

Medical University, Lucknow,

Uttar Pradesh, India

Santosh Kumar

Professor, Dept. of Orthopaedic Surgery, King George Medical

University, Lucknow,

Uttar Pradesh, India

\section{Correspondence}

Shah Waliullah

Asst Prof, Dept. Of Orthopaedic

Surgery, King George Medical

University, Lucknow,

Uttar Pradesh, India

\section{IL-17A and IL-23 cytokines and their relation with estrogen in post menopausal osteoporosis}

\author{
Shah Waliullah, Vineet Sharma, RN Srivastava, Yashodhara Pradeep, AA \\ Mahdi and Santosh Kumar
}

DOI: $\underline{\text { https://doi.org/10.22271/ortho.2018.v4.i1m.124 }}$

\section{Abstract}

Introduction: Estrogen deficiency is now considered as post inflammatory state as it has been associated with elevation of various cytokines like IL-1 IL- 6 and TNF- $\alpha$, responsible for osteoclastogenesis. Role of IL-17 has been established in various inflammatory and auto-immune disorders associated with bone loss, we evaluated the levels of IL-17 with respect to estrogen in post menopausal women with and without osteoporosis.

Material \& Methods: Total 75 post menopausal females with mean age $(58.17 \pm 5.94)$, between age group 45-75years were recruited. Females with history of natural menopause at least one year after the onset of menopause were enrolled. All patients underwent BMD measurement through Dual energy Xray absorptiometry (DEXA) scan and divided into two groups, Group A patients with osteoporosis and Group B without osteoporosis. Serum level of IL-17, IL-23 levels and Estrogen level were measured by standard quantitative sandwich ELISA kits.

Results: Group A patients level of IL-17(48.49 $\pm 8.34 \mathrm{pg} / \mathrm{ml})$ and IL-23(91.28 $\pm 9.89 \mathrm{pg} / \mathrm{ml})$ was significantly higher than in group B patients with level of IL-17(19.55 $\pm 7.11 \mathrm{pg} / \mathrm{ml})$, IL-23 $(44.56 \pm 11.36$ $\mathrm{pg} / \mathrm{ml})$ while that of estrogen was significantly low in group A $(31.80 \pm 12.57 \mathrm{pg} / \mathrm{ml})$ in comparison to group B $(40.39 \pm 20.88 \mathrm{pg} / \mathrm{ml})$.

Conclusion: We observed lower level of estrogen is associated with higher level of inflammatory cytokines IL-17 and IL-23, thus further strengthening the concept that post menopausal osteoporosis is inflammatory disorder as estrogen deficiency results in elevation of inflammatory cytokines.

Keywords: IL-17, IL-23, Estrogen, Post Menopausal osteoporosis

\section{Introduction}

Post menopausal osteoporosis defined as a silent skeletal disorder characterised by compromised bone strength predisposing to increased risk of fracture ${ }^{[1]}$. Post-menopausal osteoporosis (type I) is commonest form of the osteoporosis and is believed to start with the deficiency of estrogen following menopause ${ }^{[2]}$. Estrogen affect both osteoclast as well as osteoblast, due to deficiency of estrogen, there is incordination in activity between osteoclast and osteoblast, increased osteoclastic activity without adequate bone formation by osteoblast resulting into thinning of trabeculaes and bone resorption. Bone becomes thin, brittle and vulnerable to fracture.

Estrogen deficiency is now considered as post inflammatory state as it has been associated with elevation of various cytokines like IL-1 IL-6 and TNF- $\alpha^{[4,5,6]}$. These cytokines primarily results in osteoclastogenesis associated with estrogen deficiency.

IL-17, a unique cytokine, produced by $\mathrm{T}$ helper subset named Th17, has been linked with osteoclastogenesis in bone loss in various disorders like rheumatoid arthritis, multiple sclerosis, Crohn disease, psoriatic arthritis [7, 8, 9, 10]. Role of IL-17 in post menopausal osteoporosis has been studied in animal model and it has been found to be responsible for mediating osteoclastogenesis, we evaluated the levels of IL-17 with respect to estrogen in post menopausal women with and without osteoporosis.

\section{Material \& Methods}

This study was conducted in the department of orthopaedic surgery. Informed consent was 
taken from each subject participating in this study and ethical clearance for the study was obtained from the Ethics Committee of the university. Total 75 post menopausal females with mean age $(58.17 \pm 5.94)$, between age group 45 75 years were recruited. Females with history of natural menopause at least one year after the onset of menopause were enrolled. All patients filled a questionnaire pertaining their demographic variables, menstrual history, physical activity, exercise history and dietary intake. Females with history of surgical menopause or suffering from any chronic inflammatory disorder affecting bone turn over metabolism like chronic liver disorders, renal disorder, thyroidism, hyperparathyroidism, rheumatoid arthritis, auto-immune disorders and malignancy were excluded from our study. Patients with a history of medications like steroid intake or any other drug affecting bone turnover metabolism were also excluded.

All patients underwent BMD measurement through DEXA scan. BMD was measured at lumbar spine. DEXA scan was interpreted in terms of $\mathrm{T}$ score as per World Health Organisation $(\mathrm{WHO})$ guidelines ${ }^{[11]}$. All patients were divided into two groups, Group A patients with osteoporosis with T score lesser than -2.5 and Group B without osteoporosis with $\mathrm{T}$ score greater than-1.

Venous blood sample was collected from all subjects. After centrifugation at 4000 rotation per minute, serum was separated and stored at -80 degree celsius. Serum level of IL17, IL-23 levels and Estrogen level were measured by standard quantitative sandwich ELISA kits according to the manufacturer's instructions as per standard protocols.

\section{Results}

Group A includes 39 patients with osteoporosis (mean T score-3.61 \pm 1.06 ) and Group B includes 36 patients without osteoporosis (mean T score-0.45 \pm 1.15 ). In group A patients level of IL-17(48.49 $\pm 8.34 \mathrm{pg} / \mathrm{ml})$ and IL-23(91.28 \pm 9.89 $\mathrm{pg} / \mathrm{ml}$ ) was significantly higher than in group B with level of IL-17( $19.55 \pm 7.11 \mathrm{pg} / \mathrm{ml})$, IL-23 $(44.56 \pm 11.36 \mathrm{pg} / \mathrm{ml})$ while that of estrogen was significantly low in group $\mathrm{A}(31.80 \pm 12.57$ $\mathrm{pg} / \mathrm{ml})$ in comparison to group $\mathrm{B}(40.39 \pm 20.88 \mathrm{pg} / \mathrm{ml})$. Levels of IL-17, IL-23 and estrogens were found to be statistically significant among both groups ( $\mathrm{p}$ value<.05).

\begin{tabular}{|c|c|c|c|}
\hline & \multicolumn{2}{|c|}{$($ Mean \pm SD) } & \multirow{2}{*}{ p-value $^{\mathbf{1}}$} \\
\cline { 2 - 3 } & Group A (n=39) & Group B (n=36) & \\
\hline T Score AP Spine L1-L4 & $-3.61 \pm 1.06$ & $-0.45 \pm 1.15$ & $0.0001^{*}$ \\
\hline IL-17 (pg/ml) & $48.49 \pm 8.34$ & $19.55 \pm 7.11$ & $0.0001^{*}$ \\
\hline IL-23 (pg/ml) & $91.28 \pm 9.89$ & $44.56 \pm 11.36$ & $0.0001^{*}$ \\
\hline Estrogen (pg/ml) & $31.80 \pm 12.57$ & $40.39 \pm 20.88$ & $0.003^{*}$ \\
\hline
\end{tabular}

${ }^{1}$ Unpaired t-test, *Significant

Comparison of IL-17, IL-23 and Estrogen

\section{Discussion}

IL-17 is produced by T helper subset named Th17, has a key role in inflammatory arthritis and other diseases affecting the bone metabolism ${ }^{[12]}$. Its role in rheumatoid arthritis has been extensively studied in human as well as in animal studies. It was found to be elevated in synovial fluids of patients with rheumatoid arthritis [13, 14]. Role of IL-17 has also been extensively established with osteoclastogenesis in various auto-immune disorders associated with bone loss ${ }^{[15]}$. IL-17 has been found as crucial regulator of osteoclastogenesis associated with estrogen deficiency in animal studies. Tyagi et al. [16] studied the effect of estrogen on Th 17 differentiation and IL-17 mediated regulation of osteoclast and osteoblast in murine models. He observed that estrogen deficiency in ovariectomized mice induces Th17 cells differentiation, increased IL-17 cytokines levels and these effects are further reverse by estrogen treatment. Increased IL-17 levels were associated with decrease mineralization of bone. De Selm ${ }^{[17]}$ observed that blocking IL-17 signaling prevents estrogen deficiency mediated osteoporosis by inhibiting osteoclastogenesis in animal model.

Molnar et al. ${ }^{[18]}$ in his study on human subjects observed strong association of estrogen deficiency with elevated IL-17 level in post menopausal females. He further showed that post menopausal osteoporotic subjects have been associated with elevated level of IL-17A and soluble receptor activator of NF$\kappa \mathrm{B}$ (sRANK ligand levels), responsible for osteoclastogenesis. In our study, we also observed higher level of IL-17 in post menopausal females with estrogen deficiency. Thrawa et al ${ }^{[19]}$ also observed elevated level of IL-17 in post menopausal osteoporosis females.

\section{Conclusion}

In our study on post menopausal females, we observed lower level of estrogen is associated with higher level of inflammatory cytokines IL-17 and IL-23, thus further strengthening the concept that post menopausal osteoporosis is inflammatory disorder as estrogen deficiency results in elevation of inflammatory cytokines.

\section{References}

1. Watts NB, Bilezikian JP, Camacho PM, Greenspan SL, Harris ST, Hodgson SF et al. AACE Osteoporosis Task Force.American Association of Clinical Endocrinologists Medical Guidelines for Clinical Practice for the diagnosis and treatment of postmenopausal osteoporosis. EndocrPract. 2010; 16(3):1-37.

2. Riggs BL, Khosla S, Melton LJ. Sex steroids and the construction and conservation of the adult skeleton. Endocr Rev. 2002; 23(3):279-302.

3. Pacifici Estrogen R. cytokines and pathogenesis of postmenopausal osteoporosis. J Bone Miner Res. 1996; 11:1043-1051.

4. Eriksen EF, Hodgson SF, Eastell R, Cedel SL, O'Fallon WM. Cancellous bone remodeling in type I (postmenopausal) osteoporosis: quantitative assessment of rates of formation, resorption, and bone loss at tissue and cellular levels. J. Bone Miner. Res. 5:311-319.

5. Zhao W, Liu Y, Cahill CM, Yang W, Roger JT, Huang $\mathrm{X}$. The Role of T Cells in Osteoporosis, an Update. Int J Clin Exp Pathol. 2009; 2:544-552.

6. D'Amelio P, Grimaldi A, Di Bella S, Brianza SZ, Cristofaro MA, Tamone $\mathrm{C}$ et al. Estrogen deficiency increases osteoclast genesis up-regulating $\mathrm{T}$ cells activity: a key mechanism in osteoporosis. Bone. 2008; 43(1):92100.

7. Zhao W, Liu Y, Cahill CM, Yang W, Rogers JT, Huang $X$. The Role of $\mathrm{T}$ Cells in Osteoporosis, an Update. International Journal of Clinical and Experimental Pathology. 2009; 2(6):544-552. 
8. Kirkham BW, Lassere MN, Edmonds JP, Juhasz KM, Bird PA, Lee CS et al. Synovial membrane cytokine expression is predictive of joint damage progression in rheumatoid arthritis: a two-year prospective study (the DAMAGE study cohort). Arthritis Rheum, 2006; 54:1122-1131.

9. Stockinger B, Veldhoen M. Differentiation and function of Th17 T cells. Current Opinion in Immunology, 2007; 19(3):281-286.

10. Iannis Adamopoulos E, Edward Bowman P. Review: Immune regulation of bone loss by Th17cell. Arthritis Research \& Therapy, 2008; 10:22.

11. Kanis JA. Assessment of fracture risk and its application to screening for postmenopausal osteoporosis: synopsis of a WHO report. WHO Study Group. Osteoporos Int. 1994; 4(6):368-81.

12. Harrington LE, Hatton RD, Mangan PR, Turner $\mathrm{H}$, Murphy TL, Murphy KM et al. Interleukin-17 prodcuing CD4t effector Tcell develop via alineagedistincr from the $\mathrm{T}$ helper type 1 and 2 lineages. Nat. Immunal. 2005; 6:1123-1132.

13. Gaffen SL. Role of IL-17 in the Pathogenesis of Rheumatoid Arthritis. Current rheumatology reports. 2009; 11(5):365-370.

14. Kotake S, Udagawa N, Takahashi $\mathrm{N}$ et al. IL-17 in synovial fluids from patients with rheumatoid arthritis is a potent stimulator of osteoclastogenesis. J Clin Invest. 1999; 103:1345-1352.

15. Lacativa PGS, Farias MLF. Osteoporosis and inflammation. Arq Bras Endocrinol Metab. 2010; 54(2):123-32.

16. Tyagi AM, Srivastava K, Mansoori MN, Trivedi R, Chattopadhyay N, Singh D. Estrogen deficiency induces the differentiation of IL-17 secreting Th17 cells: anew candidate in the pathogenesis of osteoporosis. PLos one. 2012; 7(9):44552.

17. DeSelm CJ, Takahata Y, Warren J et al. IL-17 Mediates Estrogen-deficient Osteoporosis in an Act1-dependent Manner. Journal of cellular biochemistry. 2012; 113(9):2895-2902.

18. Molnar L et al. High prevalence of increased interleukin17A serum levels in postmenopausal estrogen deficiency. Menopause. 2014; 21(7):749-752.

19. Tharwa H, AL-Tai. Serum IL-17 and postmenopausal osteoporosis. J Fac Med Baghdad. 2015; 57(4):299-301. 